\title{
ALBERTO MEMBREÑO Y LA LEXICOGRAFÍA EN HONDURAS
}

\author{
Non ha mala palabra, si non es a mal tenida: \\ verás que bien es dicha, si bien fuese entendida. \\ ARCipreste de Hita, Libro de Buen Amon
}

La Editorial Guaymuras ha publicado recientemente la quinta edición de la principal obra lexicográfica, hasta la fecha, del habla hondureña. La reedición de Hondureñismos. Vocabulario de los provincialismos de Honduras (1895) ${ }^{1}$, de Alberto Membreño, añadiéndole como apéndice las ampliaciones que hizo Jeremías Cisneros ${ }^{2}$, era una necesidad sentida tanto por profesores y estudiosos del español hablado en Honduras como por sectores más amplios preocupados por la profundización del análisis de la cultura nacional. Cabe a Guaymuras, en su corta pero productiva existencia, el haber publicado en tan corto tiempo entre sus múltiples títulos dos relacionados con el habla hondureña: Hondureñismos y El refranero hondureño de Aguilar $\mathrm{Paz}^{3}$. ¡Ojalá que la adormecida Academia

${ }^{1}$ Alberto Membreño Márquez, Hondureñismos, $3^{\text {a }}$ ed., Guaymuras, Tegucigalpa, 1982. De hecho es un error considerarla $3^{\mathrm{a}}$ edición, pues en realidad es la $5^{\text {a }}$. Hasta la fecha se han realizado las siguientes:

1) Hondureñismos. Vocabulario de los provincialismos de Honduras, Tipografía Nacional, Tegucigalpa, 1895, 123 pp.

2) Hondureñismos. Vocabulario de los provincialismos de Honduras, 1897, $270 \mathrm{pp}$.

3) Hondureñismos, Müller Hermanos, México, 1912, 173 pp.

4) Hondureñismos, 1921; se trata de una reimpresión de la anterior.

5) Hondureñismos, Guaymuras, Tegucigalpa, 1982, 233 pp.

2 Cf. J. Cisneros, "Hondureñismos" en Revista del Archivo y Biblioteca Nacional, 3 (1907), núm. 5, 155-157; núm. 6, 181-183; núm. 7, 212-214; núm. 8, 250-252 y núm. 10, 313-316. 1981.

${ }^{3}$ Jesús Aguilar PAZ, El refranero hondureño, Guaymuras, Tegucigalpa, 
Hondureña de la Lengua, el remozado Ministerio de Cultura y Turismo y otras Instituciones dedicadas a la cultura tomen el ejemplo de Guaymuras!

\section{LA FORMACIÓN DE MEMBREÑO}

Es sorprendente el contraste entre la recia y relevante personalidad de Membreño, en el campo político y científico nacional, y su escasa bibliografía. Parecerían no cumplirse las proféticas y emotivas palabras que su amigo y compañero de lucha, Paulino Valladares, escribió en el diario El Cronista el día de su muerte:

Hay todavía, en muchos ánimos incultos, la hosquedad que provoca la contienda que acaba a balazos en la serranía; pero vendrán días más serenos y de mayor calma y entonces la juventud de hoy y las generaciones futuras colocarán el nombre de don Alberto Membreño en lugar preferente en la pequeña galería de nuestros grandes ciudadanos.

Membreño (1859-1921), nacido en Tegucigalpa, llega a ser alcalde de su ciudad (1887) y presidente de la República (1915). Era, según Paulino Valladares, "hombre apacible, [...] clara inteligencia $[\ldots]$ y una severidad inalterable. Solitario, $[\ldots]$ con buenos, pocos y escogidos amigos". Como si hubiera previsto el olvido a que lo ha sometido la Patria, el propio Membreño será un excelente narrador crítico de su educación formal e informal. "En la antigua Universidad de Honduras - dice- $[\ldots]$ hice mis estudios hasta obtener el diploma de abogado" (recordemos que la Academia Literaria o Universidad del Estado de Honduras no fue creada sino hasta 1849 por decreto del gobierno del Dr. Juan Lindo). Las materias que estudiaban - según Membreño- eran

español, latín, inglés, francés, matemáticas, física, filosofía, derecho civil y derecho canónico. El latín comenzó a enseñarse con la gramática de Nebrija, la que se dejó por Raimundo de Miguel; dos veces al día teníamos clase y cada una duraba, por lo menos, dos horas; para la enseñanza se dividía a los alumnos en grados, que eran declinar, conjugar el verbo sum, esse, fui; conjugar verbos activos, Corcuera, Olarte y Cuarto, con traducción de las Selectas. Diariamente recibíamos clase de español, y el texto era el de Velázquez de la Cadena, que no podía ser peor desde el punto de vista pedagógico; en mi tiempo, además de las buenas definiciones y reglas 
recopiladas por el Licenciado Máximo Gálvez, y que manuscritas circulaban, estudiábamos o consultábamos las gramáticas de Zepeda (nicaragüense); Rosales (salvadoreño), Alemany, con notas de Rocha, la Academia; Bello, con notas de Marino Ballesteros; Salvá; Martínez López y José Segundo Flores. Los textos de inglés y francés eran de Ollendorff, Robertson, Chapsal y Telémaco para traducir de este último*.

Desde la Edad Media los libros de texto eran seleccionados e impuestos a las Universidades por el poder político. Esta práctica se consagró a partir del Concilio de Trento en los Colegios y Seminarios Tridentinos. En el caso de la Universidad de Honduras, el decreto que fijaba los libros de texto data del 18 de abril de 1843; por él se restablecía el Colegio Tridentino de Comayagua. El cambio de texto de latín y la diferencia de calidad entre los libros de texto y los de consulta son un reflejo del lento proceso de cambio de la universidad escolástica del Padre Reyes a la reformada por Soto y Rosa (1882), inspirada en la doctrina liberal. El propio Membreño fue secretario general de la Universidad de Honduras, ya reformada, y aparece como tal en la primera sesión del Consejo Supremo de Instrucción Pública, celebrada el 24 de junio de 1883 .

Merece comentarse la sustitución de la gramática de Nebrija por la Gramática hispano-latina, teórico-práctica para el estudio simultáneo de las lenguas latinas y castellanas comparadas, del Dr. Raimundo de Miguel, catedrático del Instituto San Isidro, en Madrid, y autor de un diccionario latino-español que todavía se utiliza en las Facultades de Filosofía y Letras. El cambio de texto conlleva, por un lado, una notable renovación pedágogica $\mathrm{y}$, por otro, el triunfo y aceptación de la corriente comparativista surgida a partir del descubrimiento y estudio del sánscrito.

La obra de Velázquez de la Cadena no aparece registrada ni siquiera en la voluminosa Historia de la lingüistica de Arens ${ }^{5}$ y la lectura y consulta de la gramática del intelectual Vicente Salvá y la del caraqueño Andrés Bello son un reflejo del gran criterio selectivo, ya que ambas superan no sólo a la de Velázquez de la Cadena sino a la de la Real Academia.

No obstante haber cursado estas asignaturas en un tiempo mí-

4 A. Membreño, "La Universidad antes de 1878" en Revista de la Universidad, Tegucigalpa, 13 (1948), 380-382.

${ }^{5}$ HANS ARENS, La lingǘstica. Sus textos y su evolución desde la antigüedad hasta nuestros días, Gredos, Madrid, 1975. 
nimo de dos años, el propio Membreño reconoce que en la Universidad "no se enseña de filología ni siquiera nociones". Autocríticamente continúa: "sin preparación suficiente, pues, y sólo con la confianza de que por medio del estudio metódico puede cualquier persona adquirir los conocimientos que desea, comencé hace algún tiempo a acumular libros" datos para reconocer la excelente biblioteca filológica de Membreño, el cual nos muestra en los prólogos de sus obras los textos que le sirvieron de referencia y consulta, cosa poco acostumbrada por estos lares. Cualquier estudioso del español de América o de la lengua náhuatl, en la actualidad, deberá consultar muchas de las obras que menciona Membreño: Bello, Cuervo, Gagini, Rémi Siméon, Robelo, etcétera.

Otro hondureño semiolvidado, Antonio R. Vallejo, dedica su obra Ligeras observaciones al curso elemental de historia de la lengua espanola publicado en El Salvador a la memoria de sus padres ya fallecidos y "al erudito y diligente filólogo Dr. don Alberto Membreño[...] en testimonio de gratitud, por las palabras de aliento, por haber abierto las puertas de su rica biblioteca, y por el eficaz apoyo a su publicación[...] '". Un ligero recuento de las citas textuales de Vallejo nos muestra los principales estudiosos del lenguaje de Europa y América del siglo pasado: Steintal, August Schleicher, Michel Bréal, J. Grimm, Max Müller, Caro, Bello, Cuervo, etc. Sorprende en algunos casos tanto la acertada selección de obras como su rápida adquisición, envidiable aun en nuestros días; por ejemplo, Vallejo cita en 1903 la obra de Michel Bréal, Essai de sémantique, publicada en París en 1897. Bréal fue el primero en utilizar el término "semántica".

Membreño se autoformó en el estudio del léxico y adquirió cierto dominio, como él mismo reconoce, en la terminología náhuatl que pervive en Honduras y el resto de Centroamérica.

\section{LA OBRa De Membreño}

Su constante participación en la vida política de Honduras $^{8}$ no

${ }^{6}$ A. MEmbreño, Nombres geográficos indígenas de la República de Honduras, Tipografia Nacional, Tegucigalpa, 1901.

${ }^{7}$ Antonio R. VALLEJo, Ligeras observaciones al curso elemental de historia de la lengua española publicado en El Salvador, Tipografía Nacional, Tegucigalpa, 1906.

${ }^{8}$ Cf. RaMón OQueli, "Provincialismos y dos señores de antaño" en Tiempo, San Pedro Sula, 19 de enero de 1983, p. 6. 
fue obstáculo para su no muy numerosa pero significativa obra léxica. En 1895 publica Hondureñismos. Vocabulario de los provincialismos de Honduras, agotada rápidamente. En 1897 publica una segunda edición notablemente corregida y aumentada; la tercera, con ligeros retoques, se publica en México en 1912. Su segunda obra, Nombres geográficos indígenas de la República de Honduras, fue publicada en Tegucigalpa por la Tipografía Nacional en 1901. Aztequismos de Honduras, su tercera obra, fue publicada en México en $1907^{9} \mathrm{y}$, según Rafael Heliodoro Valle, es el primer libro hondureño publicado en ese país. "[ . . . Aztequismos que publicamos - dice el autor - y que diseminados constan en otras obras nuestras", no es en realidad una nueva obra, sino que, como él reconoce, ha entresacado de las dos anteriores los términos aztecas, ordenándolos alfabéticamente. Membreño publicó además, en la Revista del Archivo y Biblioteca Nacional, tres artículos: "Límites entre Honduras y Nicaragua", "La escuela pública" y "Universidad de Honduras antes de 1878".

\section{Antecedentes de la obra de Membreño}

En el ámbito nacional, los trabajos de Membreño carecen prácticamente de obras que los precedan y las que hubo, creo que no las conoció. En la época colonial debieron abundar, como en el resto de América, numerosos trabajos lingüísticos (cartillas) que fueron un maravilloso instrumento para los doctrineros. Gracias a la Real Cédula de Felipe II (1596) se eliminó la obligación para los indígenas de aprender el español, lo que obligó a que frailes y curas aprendieran las lenguas indígenas para enseñar las principales verdades cristianas. El resultado fue que se pasó de cartillas con grabados a catecismos en su mayoría trilingües: latín, castellano y una lengua indígena. Decimos que debieron abundar porque, a pesar de nuestra revisión de numerosos archivos eclesiásticos y civiles por el occidente de Honduras, no hemos encontrado ningún ejemplar. Tenemos noticias únicamente de una cartilla en lenca y español que existe en el Archivo General de Guatemala y de un léxico en que "los franciscanos y mercedarios de Comayagua envían el equivalente del vocabulario castellano en

9 También en forma incompleta apareció en la Revista del Archivo y Biblioteca Nacional, Tegucigalpa, 1907, núms. 23-24, 757-764; t. 4, núms. 1-2, 3436; núms. 3-4, 118-120. 
lengua Cavecare, Lean y Mulia Jicaque’'. Este documento será publicado próximamente.

De la época independiente conocemos únicamente la inconclusa obra de Ramón Rosa que, según el manuscrito, inició en Alajuela, Costa Rica, en la significativa fecha del 12 de octubre de 1886, bajo el título de Diccionario de centroamericanismos: la obra sólo comprende de la preposición a hasta achumicado. Dudamos que Membreño conociera el manuscrito de Rosa, que no se publicó sino hasta octubre de 1977 en una desangelada edición de la Revista de la Universidad.

En el ámbito latinoamericano, la obra de Membreño está precedida de numerosos trabajos lexicográficos, muchos de los cuales, como resalta en sus prólogos el autor, fueron obras de consulta. Citamos: Apuntaciones críticas sobre el lenguaje bogotano de Cuervo $^{10}$, Diccionario de chilenismos de Rodríguez ${ }^{11} \mathrm{y}$, sobre todo, el Diccionario de barbarismos y provincialismos de Costa Rica de Gagini ${ }^{12}$ y los Vicios del lenguaje y provincialismos de Guatemala de Batres Jáuregui ${ }^{13}$.

\section{MODIFICACIONES Y AMPLIACIONES A LA PRIMERA EDICIÓN DE HONDURENIISMOS.}

Siguiendo la línea de trabajo de Gagini y Jáuregui, la primera edición de Hondureñismos, y las que le siguieron, aparecieron con el subtítulo de "Vocabulario de los provincialismos de Honduras'. Menéndez Pidal publicó en Madrid, en la Revista Crítica de Historia y Literatura ${ }^{14}$, una reseña de la obra de Membreño. "La juiciosa crítica del notable literato español señor Menéndez Pidal - dice Membreño en el prólogo a la segunda edición- ha sido atendida como lo merece para hacer algunas ligeras correcciones en el texto, o para persistir en nuestra opinión'. Por desgracia el autor de este artículo sólo conoce indirectamente parte de la

${ }^{10}$ Rufino J. Cuervo, Apuntaciones críticas sobre el lenguaje bogotano $\left(1^{\mathrm{a}} \mathrm{ed}\right.$. 1867-1872), Instituto Caro y Cuervo, Bogotá, 1955.

11 Zorobabel Rodríguez, Diccionario de chilenismos, Santiago, 1875.

12 Carlos Gagini, Diccionario de costarriqueñismos (1 ${ }^{\text {a }}$ ed. 1892), Ed. Costa Rica, San José, 1975.

13 Antonio Batres Jáuregui, Provincialismos de Guatemala, Guatemala, 1892.

${ }^{14}$ R. MenÉndez Pidal, "Hondureñismos de Membreño: nota crítica" en Revista Crítica de Historia y Literatura, Madrid, 1 (1896), p. 75. 
nota crítica de Menéndez Pidal (aunque, según Oquelí, apareció en una publicación en La Esperanza entre 1895 y 1897).

El número de entradas (palabras, giros, locuciones, perífrasis, etc.) en la primera edición era de 1263 voces, más un suplemento de 77 vocablos recopilados por don Ignacio Fiallos. La segunda edición, según Aguilar Paz, apareció con "2071 palabras estudiadas" 15 , lo que supone un notable incremento. Eliminó, teniendo en cuenta las críticas de Menéndez Pidal, algunos vocablos y giros propios del español general y no únicamente del habla hondureña, tales como: a troche moche, cabrón, cacho, etc. Incluyó otras nuevas, sobre todo expresiones populares (a cojo pie, a la zumba marumba, a mano, a tira que no alcanza, abarrajar, abismarse, etc.) y algún refrán (a macho dado no hay que buscarle el colmillo). Incorporó algunos de los términos del apéndice de Fiallos, pero la mayoría, que eran zambos y no españoles (cume, chichi, gat, gual, gualjual, guase, laza, matagualsip, naxa, etc.) aparecerán en el vocabulario de este idioma.

La segunda edición apareció con un apéndice titulado "Breves vocabularios del moreno, zambo, sumo, paya, jicaque, lenco y chortí"'. Previamente a cada vocabulario hace un esbozo de los grupos étnicos; abundan las descripciones despectivas propias de un ladino, especialmente contra los zambos y jicaques. De los primeros dice: "son algún tanto haraganes, aficionados al licor, música y baile [...] y se asegura que amigos de cogerse lo ajeno". A los jicaques les toca la peor parte:

son éstos - dice Membreño- indios muy lujuriosos [...] es frecuente que aun el padre haga madre a su propia hija. Por esto se comprenderá que los jicaques son una raza degenerada, llegando su falta de sentimientos de dignidad humana hasta vender a sus hijos y mujeres por cualquier baratija.

En esas introducciones, Membreño muestra su trabajo de compilador, reconociendo el mérito a las personas que recogieron directamente los distintos vocabularios. De todos ellos, el que ha tenido mayor trascendencia para los estudios lingüísticos ha sido el lenca, cuyo vocabulario es una especie de testamento de la entonces moribunda lengua indígena. El vocabulario maya-chortí pierde importancia para Honduras, al ser recopilado en comuni-

${ }^{15} \mathrm{~J}$. Aguilar Paz, "Toponomias y regionalismos de Honduras" en $B 0$ letín de la Academia Hondureña de la Lengua, Tegucigalpa, 13 (1969), p. 13. 
dades guatemaltecas. La edición de Guaymuras no incluyó estos vocabularios, pero esperamos que alguna de las instituciones del Estado dedicadas al desarrollo cultural pueda hacerlo.

\section{“'Hondureñismos”' de Cisneros: UnA débil RÉPliCA}

Jeremías Cisneros (1845-1908) fue un entusiasta colaborador de Membreño en las dos primeras ediciones, como se señala en el prólogo de Hondureñismos. Cisneros en la introducción a su propia obra, en una situación comprometida, justifica así su réplica:

una vez publicada la obra [de Membreño], he llegado a notar: $1^{\circ}$ que palabras o frases de Hondureñismos tienen aquí otra estructura ortográfica; $2^{\circ}$ que muchas de esas palabras tienen aquí una acepción, si no contraria, al menos diversa; $3^{\circ}$ que la mayoría de las palabras contenidas en Hondureñismos, además del significado que ahí se les da, tienen aquí otro adicional; y $4^{\circ}$ que por acá hay voces que no figuran en Hondureñismos ${ }^{16}$.

La insistencia, como puede notarse, en los adverbios de lugar acá, aquí, es indicación de que el vocabulario de Cisneros tiene un valor local (ciudad de Gracias a Dios) y tal vez regional (Departamento de Lempira, Intibucá y La Paz).

El total de entradas en la obra de Cisneros es de 206. De ellas un porcentaje elevado aparecen en Membreño. Un análisis superficial de los términos repetidos nos muestra que muchos de ellos son vulgarismos que en la región de Gracias tienen pequeñas diferencias en su estructura fonética, tales como: variación de timbre vocálico en posición postónica; metátesis, asimilaciones, disimilaciones, sonorizaciones y sustituciones diferentes. Entre los ejemplos que citamos, el primer término corresponde a Cisneros y el siguiente a Membreño: ajuateaguate, aljeraquiento-alcaraquiento, amonos-vámonos, atrincuñar, burusco-burrusco, voto alante-vivo alante.

Abundan en la obra de Cisneros vocablos de origen náhuatl con significación ampliada o diferente a la de Membreño: cuije, curunco, Chirota, chinga, cuajilote, etc. Otros nahuatlismos aparecen únicamente en Cisneros, tales como: chilca, chilizate, chinamo, chorempa, chuncucuyo, etcétera.

${ }^{16}$ J. Cisneros, "Hondureñismos" en Revista del Archivo y Biblioteca Nacional, 3 (1907), núm. 5, p. 155. 
Otro notable grupo de palabras del habla de Gracias son arcaísmos que no aparecen en Membreño o tienen significación diferente. Honduras es un área rica en arcaísmos, pero en Gracias y el resto del área de Occidente son especialmente abundantes. Entre otros, Cisneros cita: aguanoso, alafia, baldioso, lamber, 1óbrigo, mujerengo, (a)persogar, etcétera.

Finalmente hay un pequeño número de palabras de origen incierto, que en su mayoría pueden ser sustratos léxicos de la lengua lenca en su variante dialectal de Cerquín ${ }^{17}$, hablada en esa área hasta finales del siglo XVIII. Es todavía prematuro señalar cuáles pueden ser los términos lencas, dado el escaso número de vocabularios recopilados hasta la fecha: $\operatorname{Lehman}^{18}$, Campbell ${ }^{19}$, Campbell y Chapman ${ }^{20}$ y Salgado S $^{21}$

Las causas que explican las características léxicas de Gracias y su comarca son complejas. Gracias fue fundada por los españoles en 1536 y pasó a ser sede de la Audiencia de los Confines de 1544 a 1548. Progresivamente, hasta nuestros días, sufrió un decaimiento económico y un aislamiento que han favorecido la pervivencia de arcaísmos. El elevado número de voces nahuas en el área de Gracias se debe a los asentamientos de mexicas que los conquistadores españores hicieron en esa región. Especial mención merece la reducción de Mexicapa, pueblo de mexicas ubicado en las puertas de Gracias para defender la ciudad de los aguerridos lencas y que hasta la fecha mantienen encuentros anuales (guancaseos) entre ambas comunidades ${ }^{22}$. A esto debemos añadir gran número de documentos coloniales que muestran que en la mayoría de pueblos del Partido de Gracias se debían nombrar doctrineros que dominaran la lengua mexica o naguate y que en los juicios de residencia, hasta el siglo xviII, en el área de Gracias era frecuente nombrar traductores en lengua mexica ${ }^{23}$.

17 Anne Chapman, Los lencas de Honduras en el siglo XVI, Instituto Hondureño de Antropología e Historia, Tegucigalpa, 1978, p. 25.

18 W. Lehman, Zentral Amerika, t. 2, Berlín, 1920, pp. 671-682.

19 L. Campbell, "The last Lenca', International Journal of American Linguistics, 42 (1976), 73-78.

${ }^{20}$ L. Campbell, A. Chapman y K. Dakin, "Honduran Lenca", International Journal of American Linguistics, 44 (1978), 330-332.

21 Mariana Salgado et al., Estado actual de la lengua lenca, Universidad Nacional Autónoma de Honduras, Tegucigalpa, 1981, pp. 98-114 (Tesis).

22 Nolvia Ponce et al., Los guancasos en Honduras, Universidad Nacional Autónoma de Honduras, Tegucigalpa, 1982, pp. 76-79 y Anexo V, pp. 1-17 (Tesis).

${ }^{23}$ Mario Felipe Martínez, Presencia de grupos mexicanos antes y después de 
Hablar de su influencia es en la práctica hacer una historia de la lexicología del español en Honduras. Aquí señalaremos críticamente los trabajos más conocidos sobre esta materia. El Boletín de la Academia Hondureña de la Lengua publicó entre 1955 y 1956 varios glosarios de hondureñismos y regionalismos. Estos trabajos se iniciaron a raíz de la iniciativa de la Real Academia Española de la Lengua que, a través de la Comisión de Lexicografía, presidida por don Julio Casares, motivó a todas las Academias de Lengua Española para que recopilaran y presentaran vocabularios de voces y giros propios de cada país a la citada Comisión. El objetivo final era, y sigue siendo, incorporar a la nueva edición del diccionario de la Corporación 20000 voces provenientes del español de América y Filipinas. Personalmente trabajé en esta labor de compilación y selección de la Academia en los años de 1969 y 1970, y el trabajo apenas llegaba a la letra B.

La desordenada publicación de la Academia Hondureña de la Lengua sobre voces y giros propios del español de Honduras muestra la carencia de especialistas y de coordinación en un organismo que debe velar por la pureza del idioma, así como objetivos poco delimitados y ausencia de una metodología de investigación científica. De los vocabularios publicados en el Boletín, el más completo (1309 hondureñismos) es el recopilado por el académico don Carlos Izaguirre, titulado "Vocablos, giros y locuciones más corrientemente usados en Honduras". La obra de Izaguirre es inferior a la de Membreño y contiene errores de forma y fondo imperdonables. Elegimos al azar un vocablo que incluyen ambas obras: lencas o lenca (transcribo únicamente la definición de Izaguirre, pues la de Membreño pueden consultarla en la nueva edición):

Lencas: m. pl. Indios que poblaban en la parte central de Honduras, especialmente en los Departamentos de Comayagua y Tegucigalpa. Se les conoce con los nombres de payas e hicaques o xicaques, y viven actualmente en gran parte de la meseta de la Montaña de La Flor.

Confundió tres grupos étnico-lingüísticos, hoy todavía claramen-

la conquista de Honduras y pervivencia de la lengua náhuatl en el área supuestamente len$c a$, Ed. Universitaria, Tegucigalpa, 1981, pp. 10-12. 
te diferenciados, en uno, y ubicó a lencas y payas en los predios de los jicaques.

Otra obra es la que Rosalío Zavala publicó en Bogotá con el título de "Hondureñismos" como apéndice del Diccionario escolar de lengua castellana ${ }^{24}$. Si se toma el lector la molestia de comparar la lista de entradas y artículos (explicaciones de cada palabra) confirmará la gran similitud con la obra de Membreño.

Mejor que la de Membreño en la clasificación y origen de palabras es "Toponimias y regionalismos de Honduras" de Aguilar Paz publicada originalmente en el Boletín de la Academia Hondureña de la Lengua ${ }^{25}$. Es una obra muy corta, de redacción y publicación un tanto caótica, pero con acertados criterios lingüísticos (clasifica algunos hondureñismos con base en el substrato o adstrato de la lenguà indígena de que proceden). "El taíno o caribes", náhuatl y miskito son los substratos y adstratos estudiados.

La obra de Membreño, especialmente la toponímica, ha tenido seguidores en varios países centroamericanos y en México. En Nicaragua, por ejemplo, Alfonso Valle, padre de la filología nicaragüense, publicó en la revista Nicaragua Indígena un trabajo titulado "Las etimologías del doctor Membreño". En México el Diccionario de aztequismos (1974) de Luis Cabrera reconoce algunas etimologías nahuas de Membreño como más correctas que las de Cecilio A. Robelo.

\section{Limitaciones de La OBRa De Membreño}

Uno de los conceptos más complejos y discutidos en lingüística ha sidó y es el de dialecto. El concepto de dialecto implicaba términos como región, provincia, pueblo, etc. pero en la actualidad estos términos se consideran producto de divisiones políticoadministrativas que no concuerdan con los compartimientos de las lenguas. Las fronteras lingüísticas de Centroamérica y, en especial, de Honduras, no coinciden en absoluto con las nacionales, departamentales o locales; de ahí el problema teórico que se plantea al utilizar expresiones como hondureñismos, olanchanismos, etc. No obstante lo anterior, Membreño, con criterios muy acertados para su tiempo, consideró hondureñismos por una par-

${ }^{24}$ R. ZAVALA, "Hondureñismos"' en Diccionario escolar de la lengua castellana, Bogotá, 1964, pp. 345-449.

${ }^{25} \mathrm{~J}$. Aguilar Paz, art. cit., 3-40. 
te las toponimias, los nombres de "cosas indígenas de uso común" y los nombres de vegetales y animales "que no constan en obras de botánica y zoología" (es decir, todos los substratos o adstratos de lenguas indígenas) y por otra, las voces del español que han caído en desuso en otras áreas (arcaísmos), las voces corrompidas del castellano (vulgarismos) y aquellas castellanas que han modificado o ampliado su campo de significación en nuestro contexto. En el estudio de los substratos y adstratos indígenas, Membreño descubrió que muchos provenían del náhuatl. En Hondureñismos aparece un mínimo de 207 voces de procedencia azteca y en Nombres geográficos indígenas de la República de Honduras, de los 947 topónimos la mayoría los consideró de origen náhuatl. Pero el náhuatl proveniente de México se extendió en diversos momentos históricos (precolombino y colonial) y por diversas causas (dominación, enclaves, lengua general de los doctrineros), en Honduras y el resto de Centroamérica; en consecuencia, gran número de voces tendrán vigencia no sólo en un nivel nacional, sino en toda el área centroamericana.

Aquí es donde Membreño incluye como hondureñismos vocablos que en realidad son centroamericanismos, como por ejemplo: ayote, ayotera, atoleadas, caite, papalote, coyol, caceste, guajiniquil, chilate, etcétera.

La marcada tendencia de Membreño a buscar raíces nahuas, especialmente en topónimos, inconscientemente lo alejó del caudal de voces provenientes de lenguas indígenas propiamente nacionales (lenca, maya-chortí, ulúa, paya, etc.) y en consecuencia lo llevó a una excesiva nahuatlización de la toponimia hondureña. En su obra toponímica incluye con algún margen de duda, como sufijos de procedencia náhuatl, gua-, -teca, -tique y -terique. Después de los estudios de Lehman ${ }^{26}$ y Anne Chapman ${ }^{27}$, estos sufijos se consideran de origen lenca. Chapman considera como lencas los siguientes: güiran, guirán, huiran $=$ pueblo; terique $=$ cerro; quin = camino; guara, ugara, huara, guala = río; guas, güas, guaz, uash = agua; tega teja, teca $=$ llanura o valle; $\operatorname{cogton}=$ montaña; $t^{\prime} a u$, taug, thau = casa; lepa $=$ jaguar, denominado león por los españoles.

La segunda observación trata de mostrar que algunas de las palabras que Membreño considera hondureñismos son voces de dominio general o regional de uso en otras partes de América o España. Sobre este punto consideramos válidas las críticas de Me-

${ }^{26}$ W. LEHMAN, op. cit., t. 2, pp. 624-625 y 671-682.

${ }^{27}$ A. Chapman, op. cit., p. 38. 
néndez Pidal ${ }^{28}$ y de $\mathrm{J}$. de Barcelona ${ }^{29}$. Entre las palabras que mencionan en su crítica como de uso general del español y que sin embargo Membreño incluye como hondureñismos, están: alcancía, cantina, embarrar, inscribir, indino, barbasca (varbasco por la Academia) y otras.

La tercera observación es de carácter técnico. Tomaremos los basamentos teóricos y técnicos dominantes en la época de Membreño y expresados por Menéndez Pidal en un artículo titulado "El diccionario ideal" 30 . Menéndez Pidal, después de hablar de los tipos de diccionarios, indica las dos grandes vertientes que abarca toda obra léxica: el caudal de voces y el modo de exponer este caudal.

El caudal léxico debe comprender, para Menéndez Pidal, las voces literarias, los neologismos, arcaísmos y localismos. En la segunda edición, debido a las críticas, Membreño incorporó un mayor número de voces y giros del habla popular hondureña, pero dejó fuera muchos de los neologismos y tecnicismos de la época. En el modo de exponer el caudal léxico, Menéndez Pidal señala que deben incluirse la etimología, fecha de aparición de la palabra, acepciones, definición, sinónimos, localización de su uso, accidentes gramaticales y voces despectivas y eufemísticas. Membreño excluyó algunos de estos aspectos, explicando en el prólogo las causas de su acción:

Nada decimos de los vicios del régimen y construcción, porque hasta el presente no tenemos más autoridad que el trabajo compendiado sobre régimen que publicó en su Gramática la Real Academia Española, y el Tomo I del Diccionario de construcción y régimen de Rufino José Cuervo (todavía hoy inconcluso). Cuando esta última obra esté concluida para honra de las letras hispano-americanas, tal vez acometamos la empresa de adicionar nuestro trabajo en la parte relativa a sintaxis.

Más adelante reconoce que "tampoco se extiende nuestro estudio a materias de prosodia..."; no obstante estas limitaciones, están bien trabajados por Membreño aspectos tales como definiciones, acepciones, sinónimos y voces despectivas y eufemísticas.

28 R. Menéndez Pidal, loc. cit.

${ }^{29}$ J. DE Barcelona, “Hondureñismos, Nota crítica" en La Unión, Tegucigalpa, 23 de abril de 1898 , p. 1.

30 R. MEnÉndez PIDAL, "El diccionario ideal" en Estudios de Lingüística, $2^{\mathrm{a}}$ ed., Espasa-Calpe, Madrid, 1970, pp. 93-147. 
Finalmente recalcamos que la obra de Membreño sigue siendo el trabajo lexicográfico más valioso sobre el español hablado en Honduras. El lector actual de Hondureñismos debe ubicar la obra en su contexto histórico y tener en cuenta que en la actualidad cierto número de palabras registradas como de uso común en Honduras son restringidas a áreas rurales; otro grupo de voces han caído en desuso, algunas han modificado o ampliado su campo semántico y otras nuevas no están registradas, como es lógico, en la obra de Membreño.

Quisiera hacer mías las palabras de don Jesús Aguilar Paz, que al hablar de Membreño se expresaba así:

Nos ha dejado una obra valiosa sobre filología nacional digna de todo encomio, por lo cual merece el reconocimiento de la Patria y un espontáneo homenaje de parte de la Academia Hondureña de la Lengua, del pueblo y del gobierno hondureño ${ }^{31}$.

Atanasio Herranz Universidad Nacional Autónoma de Honduras 